This pattern of findings is consistent with the notion that unsignaled US interfere with CER conditioning to the degree that they increase S's fear of situational cues in the context of which the CS is trained. When this fear is diminished by additional exposures to the situational cues in the absence of the US, the interfering effect of the unsignaled USs upon CER conditioning is also diminished.

The theoretical formulations of Wagner (in press, $a, b$ ) and Rescorla (in press), which have been grossiy summarized, anticipate such effects. Any procedure which is successful in increasing the fear-producing properties of those cues with which the CS is presented in compound would be expected to result in smaller increments in the CER to the CS on reinforced trials, and in larger decrements in the CER to the CS on nonreinforced trials. Any procedure which is successful in decreasing the fear-producing properties of those cues with which the CS is presented in compound would be expected to result in larger increments in the CER to the CS on reinforced trials, and in smaller decrements in the CER to the CS on nonreinforced trials.

The present findings would not be predicted by a local interference interpretation of the influence of unsignaled USs. It might be suspected, however, that unsignaled USs simply reduced the overall rate of drinking during the test session, so that the CS only appeared less effective in Group $U$ as a consequence of being evaluated upon an already depressed and insensitive base-line. It is important, then, to note that following the drinking retraining day there were no longer any detectable systematic differences in behavior among the four groups in the absence of the CS, and that the low suppression measure to the CS in Group $U$ during testing was associated with a higher absolute number of lick responses during the $C S(M=378)$ than was observed in any of the remaining three groups $(M=318,306$, and 256$)$. It thus appears that the critical variable in the present experiment was the fear engendered by the situational cues during conditioning rather than during testing.

Regardless of the theoretical interpretation, the present findings are clear in revealing a contextual dependence in the influence of CS-US contingencies. There was no difference in the correlation between CS and US occurrence in Groups $U$ and $U$-add, as computed within the daily CER conditioning session. Since neither of these groups was exposed to either the CS or US outside of this daily conditioning session, there was also no difference in the correlation between CS and US occurrence as compuied over $S$ 's entire daily experience.

What did differ was the degree of correlation between CS and US occurrence in Groups $U$ and $U$-add as computed over the total time spent in the experimental chamber. There was, therein, a considerably higher correlation in Group U-add than in Group $\mathrm{U}$, as the additional sessions served to reduce the overall relative frequency of US occurrence in the absence of the CS.

Thus, the different degrees of suppression observed in Groups $U$ and $U$-add may be viewed as consistent with the different CS-US correlations which were arranged in the two groups. But such a view requires an explicit recognition of the role played by those contextual cues which define the experimental environment within which these correlations are computed. \section{REFERENCES}

KAMIN, L. J. Predictability, surprise, attention, and conditioning. In B. Campbell and R. Church (Eds.), Punishment and aversive behavior. New York: Appleton-Century-Crofts, in press.
RESCORLA, R. A. Predictability and number of pairings in Pavlovian fear conditioning. Psychonomic Science, 1966, 4, 383-384.

RESCORLA, R. A. Pavlovian conditioning and its proper control procedures. Psychological Review, 1967, 74, 71-80.

RESCORLA, R. A. Probability of shock in the presence and absence of $C S$ in fear conditioning. Journal of Comparative \& Physiological Psychology, 1968, 66, 1-5.

RESCORLA, R. A.Conditioned inhibition of fear. In W. Honig and N. Mackintosh (Eds.), Fundamental issues in associative learning. Halifax, N.S.: Dalhousie University Press, in press.

WAGNER, A. R. Stimulus validity and stimulus selection in associative learning. In W. Honig and N. Mackintosh (Eds.), Fundamental issues in associative learning. Halifax, N.S.: Dalhousie University Press, in press, a.

WAGNER, A. R. Stimulus selection and a "modified continuity theory." In G. H. Bower and J. T. Spence (Eds.), The psychology of learning and motivation. Vol. 3. New York: Academic Press, in press, $b$.

NOTE

1. This research was supported in part by NSF Grant GB-6534.

\title{
Reinforcement of shock-induced fighting
}

PAUL I. DREYER and RUSSELL $M$. CHURCH, Brown University, Providence, R.I. 02912

Twelve rats were given a fixed number of inescapable electric shocks in a T-maze.
Under these conditions, Ss chose to run to the end of the arm containing another rat and engaged in the stereotyped shock-induced fighting. This choice supports previous studies showing that the opportunity for aggression is a 
reinforcement of behavior of $S$ s receiving inescapable shock.

When brief, but intense, pulses of electric shock are presented to a pair of rats in a small cage, they engage in stereotyped fighting. Between shocks, they stand on their hind legs facing each other, with their front legs extended in a "boxing" position. During and just after each pulse of shock, they bat at each other. This behavior has been called "reflexive fighting" (Ulrich \& Azrin, 1962), and much of the previous research has been concerned with such parameters of the unconditioned stimulus as intensity, duration, and frequency (e.g., Dreyer \& Church, 1968; Ulrich \& Azrin, 1962).

Under the appropriate motivational conditions, the opportunity to attack another animal or an inanimate object may reinforce instrumental behavior. Squirrel monkeys given tail shocks will learn to pull the chain that produced an attackable canvas ball (Azrin, Hutchinson, \& McLaughlin, 1965); cats given hypothalamic stimulation choose the arm of a Y-maze in which there was an attackable rat (Roberts \& Kiess, 1964); Siamese fighting fish will perform a response that produces a mirror image that elicits an aggressive response (Melvin \& Anson, 1969); mice choose the arm of a $\mathrm{T}$-maze containing a dangled victim mouse (Tellegen, Horn, \& Legrand, 1969); rats that kill mice choose the arm of a T-maze containing an attackable mouse, while nonkillers choose the other arm containing a rat pup (Myer \& White, 1965). There is nothing incompatible between the eliciting and reinforcing function of a stimulus. Apparently, animals of various species may seek to expose themselves to conditions that elicit aggressive responses.

The present study was an attempt to determine if the opportunity for aggression during noncontingent shocks would serve as a reinforcement of the behavior of the Norway albino rat.

\section{APPARATUS}

A T-maze with an electrifiable grid floor was used to test the choice behavior. The stem of the T-maze was 16 in., including a 5 -in, starting compartment separated by guillotine doors, and each of the arms was $18 \mathrm{in.}$ long. The walls and top were constructed of clear acrylic, and each section was $103 / 4$ in. high and $33 / 4$ in. wide. A target rat could be restrained at the end of either arm by hooking a piece of plastic that was taped to the tail to a fastener located outside, the arm. A matched-impedance source (DSI 276 generator) delivered a shock of approximately $2.0 \mathrm{~mA}(300 \mathrm{~V}$ through
$150 \mathrm{~K}$-ohm resistor) through a grid scrambler (DSI 255) to $S$.

SUBJECTS AND PROCEDURE

The Ss were 12 experimentally naive Norway albino rats (Charles River CD). They were 70 days old at the beginning of the experiment, and they were fed a daily ration of about $14 \mathrm{~g}$ of Purina chow mixed with about $25 \mathrm{~g}$ of water.

The target rat was always at the end of the left arm for a randomly selected half of the Ss and always at the end of the right arm for the remaining Ss. At the beginning of each trial, $S$ was placed in the starting compartment, and it was given $152-\mathrm{mA}$ shocks of $1 / 2-\mathrm{sec}$ duration spaced $3 \mathrm{sec}$ apart. Immediately after the first shock, the guillotine door was opened, and $S$ could remain in the stem, enter either arm, and retrace at will. Regardless of its behavior, $\mathrm{S}$ received the 15 shocks. Each $\mathrm{S}$ received 25 trials spaced at an intertrial interval of about $1 \mathrm{~min}$. Records were kept of the arm that $S$ first entered on each trial, the location of $S$ during each shock, and the number of fighting responses. A fighting response was defined as physical contact of a lunge, strike, or bite by either $S$ or the target rat from the stereotyped boxing posture. The target rat was partially protected from the shock by wearing a rubber boot.

\section{RESULTS}

Typically, S would run directly to the end of the arm containing the other rat and begin to fight. The median $\mathrm{S}$ received $90 \%$ of its shocks in the arm containing the other rat and, excluding the few shocks that were received in the stem, $95 \%$ of the remaining shocks were received in the arm containing the other rat. A fighting response was recorded on $59 \%$ of the shocks in the case of the median S. The

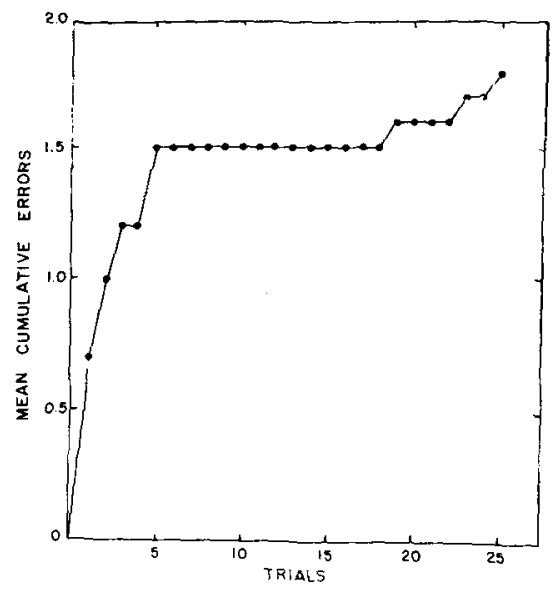

Fig. 1. Mean cumulative number of errors on the 25 trials for the 10 Ss with a significant preference for the arm with the target rat. data on the arm of the T-maze first entered by $S$ on each trial make it clear that $S$ sid not choose the arm at random and remain mostly with the other rat because they were "trapped" by the fight. The Ss made a median of 23 of their 25 initial choices to the arm with the target rat, and 11 of the 12 rats made a majority of their initial choices to the arm with the target rat $(p<.005)$. Only two of the Ss did not demonstrate a significant preference for one of the two arms. The $10 \mathrm{Ss}$ that demonstrated a preference for the arm with the target rat made a total of only 18 errors (out of a possible 250), and these were primarily concentrated on the first few trials before the Ss had learned the location of the other rat.

\section{DISCUSSION}

Ulrich \& Azrin (1962) reported that the percentage of shocks eliciting a fighting response of the Norway albino rat rapidly decreased as the area of a square chamber was increased. When the chamber was 6 in. on a side, about $90 \%$ of the $2.0-\mathrm{mA}$ shocks elicited fights; when it was 12 in. on a side, about $60 \%$ of the shocks elicited fights; and when it was 24 in. on a side, about $2 \%$ of the shocks elicited fights. The present apparatus was longer than 24 in. but narrow. Thus, when the two rats were near one another, they were necessarily in the face-to-face posture. Under these conditions, the stereotyped fighting induced by electric shock was not simply an unconditioned defensive response because most Ss ran rapidly to the other rat. The opportunity for aggression during noncontingent shock is a reinforcement of choice behavior of the Norway albino rat.

\section{REFERENCES}

AZRIN, N. H., HUTCHINSON, R. R., \& McLAUGHLIN, R. The opportunity for aggression as an operant reinforcer during aversive stimulation. Journal of the Experimental Analysis of Behavior, 1965, 8, 171-180.

DREYER, P. I., \& CHURCH, R. Shock-induced fighting as a function of the intensity and duration of the aversive stimulus. Psychonomic Science, 1968, 10, 271-272.

MELVIN, K. B., \& ANSON, J. E. Facilitative effects of punishment on aggressive behavior in the Siamese fighting fish. Psychonomic Science, 1969, 14, 89-90.

MYER, J. J., \& WHITE, R. T. Aggressive motivation in the rat. Animal Behaviour, 1965, $13,430-433$.

ROBERTS, W. W., \& KIESS, H. O. Motivational properties of hypothalamic aggression in cats. Journal of Comparative \& Physiological Psychology, 1964, 58, 187-193.

TELLEGEN, A., HORN, J. M., \& LEGRAND, R. $G$. Opportunity for aggression as a reinforcer in mice. Psychonomic Science, 1969, 14, 104-105.

ULRICH, R., \& AZRIN, N. H, Reflexive fighting in response to aversive stimulation. Journal of the Experimental Analysis of Behavior, 1962, $5,511.520$. 